\title{
Over her dead body: Expelling the monstrous- feminine in Touching Earth Lightly
}

\author{
Kathryn James
}

Death and sex/uality are inextricably linked in the Western cultural imagination. The French slang term for 'orgasm' (la petite mort) is said to literally translate as 'little death', for instance, while the 'sex-leading-to-death' motif is pervasive in narrative and aesthetic representations. Although not always consciously articulated, throughout history the most fundamental taboos on human behaviour have also been those concerned with death and sexual functions (McNay 1994, p.41). Much of the work of cultural theorists Sigmund Freud, Georges Bataille and Julia Kristeva intersects around this idea as well. Freudian psychoanalytic theory is based upon the notion that the psychic life of the subject is governed by two antagonistic biological or instinctual urges - one toward reproduction, and the other toward destruction. In Bataille's view, the framework of the law that shapes the subject (the processes of socialisation) is associated with the expulsion of the 'accursed share'- that portion of the self that is bodily and material: forbidden eroticism (incest), excrement, and death (the return to material nature of human life) (Rivkin \& Ryan 1998, p.337). An 'aura of death is what denotes passion', Bataille contends (1986,p.20) because at the same time that humanity pushes death away by trying to exclude what is horrifying, it is drawn (or desires) to approach what threatens (Hegarty 2000, pp.61-62). ${ }^{2}$ Kristeva makes a similar claim when she argues that erotic pleasure emerges as a symbolic response to the uncontainable threat of mortality. For Kristeva, the erotic is both a reaction to the threat of castration and an attempt to sustain life itself in the face of death (Tanner 1996).

In The Body's Perilous Pleasures, Michele Aaron points out that the combination between pleasure (sexual expression) and danger (potential death) is one that 'seems always to leak out of society's unconscious into its perilous, if ostensibly innocent representations' (1999, p.10). It is over representations of the dead feminine body, however, that this relationship between mortality and sexuality is especially pronounced. Indeed, for centuries, death and Woman have been wedded together so firmly in art and literature that, to appropriate Kerry Mallan's words, we have come to see the deaths of women as 'fatal attractions calling a crowd of onlookers and inviting close inspection' (2002a, p.175). Woman is 'a symptom of death's presence',
Elisabeth Bronfen argues, 'precisely because she is the site where the repressed anxiety about death re-emerges in a displaced, disfigured form' (1992, p.215). According to Efrat Tseëlon, Woman simultaneously 'serves the dual function of signifying a fear and the defence against' death (1995,p.101). Woman and death share many characteristics, Tseëlon argues: in the same way that the sight of the female body triggers male anxiety of castration, the sight of the dead body triggers anxiety of mortality. Thus, in patriarchal societies, both are mysterious, ambiguous, silent, unrepresentable and a threat to stability, both are the eternal Other, and both are a metaphor of disruption and transgression (1995, p.113).

The figure of the female prostitute has always been a pervasive signifier of potential danger, source of infection and fatal punishment in the Judaeo-Christian narrative tradition, for example. Here, cultural anxiety is located in the 'excessive' sexuality of the female, making the death of the prostitute a cure, a punishment, or a way to contain the threat she poses to the heterosex and the patriarchy. As Sander L. Gilman's examination of a variety of nineteenthcentury images and texts featuring dead prostitutes suggests, the prostitute's death expiates her 'sins against the male' (1993, p.263). The prostitute's perversion (which is associated too with her relation to capital and the power of money) also constructs her as an 'enemy within the body politic', as corrupt and dangerous, Elisabeth Bronfen and Sarah Webster Goodwin argue- - hence the need to have her destroyed (1993, p.18).

The argument that literal or symbolic death represents one of the ways that the 'perverse' body can be removed from the sexual economy (and thus work to reinforce the heterosexual norm) is a theme I wish to take up in this paper. The conceptual foundation upon which I base this argument is drawn from Michel Foucault's work on sexuality and body politics. For Foucault, sex and sexuality 'together comprise a set of practices, behaviours, rules and knowledges' by which an individual produces itself and is produced as a 'knowing' — ethical, social and juridical-subject. Sex/uality is tied up with meanings and power because subjects (and bodies) are written and regulated by, or are the product of various institutional practices, ideologies and discourses (Danaher, Schirato \& 
Webb 2000, p.136). It is through the transformation of sex into discourse, Foucault argues, that our epoch has 'initiated sexual heterogeneities', expelling from 'reality' the forms of sexuality 'that are not amenable to the strict economy of reproduction' and thus creating a 'norm' of sexual development (1978, pp.36, 37). In this way, 'appropriate' sexual behaviours are defined, sexual irregularity is annexed to pathology and alternative forms of non-reproductive sexuality are branded 'perversions'.

In order to explore these ideas in more detail, I wish to focus on Margo Lanagan's Touching Earth Lightly(1996), a text which not only represents death as a significant event influencing the development of the adolescent female subject, but which also frames mortality through themes of sexuality. The text makes an interesting study-firstly, because it has the potential to interrogate a number of familiar masculinist representations of women within Western discourses; secondly, because it engages so closely with woman/death, that twin 'enigma' which Western culture posits as what is 'radically other to the norm, the living or surviving masculine subject' (Bronfen \& Goodwin 1993, p.13); and, thirdly, because, although it offers open resistance to orthodox ideas about what constitutes acceptable sexual behaviour and practices, at the same time it is evident that conflict surfaces between what the text represents in the narrative and the processes of representing it.

The novel explores notions of femininity and the female body through two very different protagonists. One girl, Chloe, is conventionally beautiful, caring and interested in romantic love, possessing qualities typically associated with orthodox models of femininity. Janey, the other, is by contrast promiscuous, reckless and wild. Their particularly close relationship is the focus of the narrative; however, it is a story of female friendship that is tinged with sadness since Janey dies part of the way through its telling. For Chloe, Janey's violent, sordid death means that there is 'a dark wound in her where Janey [has been] cut off', a wound that 'never quite closes [but] sours everything, slows everything, bleeds mystery and sadness' (p.169). But it also signals her own growth, away from the timeconsuming and sometimes suffocating relationship she has with Janey.
Roberta Seelinger Trites argues that 'an acceptance of losing others and awareness of mortality' shapes much of the discourse surrounding death in YA novels, because adolescents commonly gain their first knowledge of the pain and powerlessness involved in permanent separation when someone they love dies. The 'corollary that inevitably follows', Trites contends, is the 'recognition of their own mortality' (2000, p.119). Demonstrating Chloe's own acceptance as Being-towards-death, Janey's death makes Chloe feel 'as if she's just a cipher for her dead friend, as if she's death itself' (p.151), and also gives her life some significance - 'an edge of portent, a kind of unwitting courage it didn't have at the time'(p.168). ${ }^{3}$ However, because in many ways, Chloe and Janey believe that 'together [they] make up one gifted, gorgeous person' (p.139), Janey's death is also an extremely important aspect of the narrative's ideological framework. When the two girls greet each other, for instance, 'it's as if the remaining part of [their] self has appeared' (p.163). And yet, at the same time that descriptions of them focus on their extreme closeness, they also emphasise - in unequal terms - their difference, contrasting physical appearance, class and, in particular, attitudes towards sex and sexuality. As Clare Bradford points out, for a number of reasons, the construction of the girls' relationship through a scheme of binary oppositions is problematic: it consistently undermines Janey's search for agency by depicting her as 'abnormal' next to the uncomplicated and under-control Chloe; it associates class difference with sexual pathologies; and it creates a kind of determinism for Janey (1998, pp.114-116). Readers are thus cued to not only to expect Janey's exit from the narrative but to see it as a consequence of her risky behaviour, her social position and her way of being female.

According to Robyn McCallum, the double in adolescent fiction can be represented as an aspect of the developmental process; that is, 'the double represents another possible position the character might occupy'(1999, p.77). In a sense, Janey operates as Chloe's double: under McCallum's terms, she is 'an other', but most importantly, 'another' aspect of the self — an internalised other (1999, p.75). This is evident in the way that Janey never 'speaks' her self in the text but is rather focalised always through Chloe (Bradford 1998, p.114). Chloe perceives herself to be colourless, boring 
[and] directionless', and Janey as marvellous, with 'all the talent, all the sex appeal [and] all the initiative' (p.130). Yet because of the pejorative construction of Janey's sexuality, at a psychological and figurative level, she becomes a manifestation of the most threatening or dangerous aspects of Chloe's self. In Freudian psychoanalytic terms, Janey represents Chloe's id, her instinctual, biological drives and desires. In the face of the socially controlled dictates of the super-ego, however, she is forced to operate as a monster of excess. Like the nineteenth-century literary figure of the madwoman in the attic - that repressed aspect of the (female) self that is confined by the dictates of patriarchy (Gilbert \& Gubar 1979) — Janey functions as an asocial and uninhibited surrogate for the conventional, nicely brought-up, often docile Chloe. In ways similar to other representations of psychological doubles, the two are juxtaposed to reflect this: Janey is dark where Chloe is fair, and Janey is 'oversexed' and passionate in contrast to Chloe who is 'happy-ish' and not particularly interested in sexual activity (p.39). Symbolically, then, when Janey dies, Chloe's body hurts, 'actually hurts!' [original emphasis] (p.131), and her period arrives early to 'make the bleeding literal' (p.120). As the reference to menstrual blood (a signifier of Woman) indicates, here it is as if Janey - and therefore the monstrous aspect of Chloe's sexuality-is being expelled, for in Kristeva's view, menstrual blood 'stands for the danger issuing from within identity (social or sexual)'(1982,p.71). As Elizabeth Grosz explains, 'proper' sociality and subjectivity are based on the expulsion of the improper, the unclean, and the disorderly elements of the body's corporeal existence from its 'clean and proper' self, and thus 'the subject must disavow part of itself in order to gain a stable self' (1990, p.86).

Kim Wilson's more literal reading of Janey's death argues that it is 'a function of the plot to illustrate the effect of abjection on subjective development' (2001, p.27). ${ }^{4}$ For Janey is abject: she can see that her 'whole life disgusts people' because it is 'a big dirty hole that [she is] always having to be dragged out of' (p.82). Janey is also an example of what Barbara Creed calls 'the monstrous-feminine'. According to Creed, representations of the monstrousfeminine are, in psychoanalytic terms, manifestations of male castration anxiety, and thus their presence in a text typically operates to reinforce the phallocentric notion that female sexuality is abject (1993, p.151). This is signalled by the way her character is constructed as a 'devourer' and as a threat to the males she engages with. When Chloe suggests that Janey needs a 'nice, steady, tolerant man' such as her brother Nick, he protests: 'She's dangerous, that girl ... God, she'd take over [and] I don't think there's enough of me ... I've got a life to live' (p.128). Her monstrosity is starkly evident too in another episode very early in the novel where she is likened to a deadly spider: 'The moonlight fell through the car window onto Janey's tight black-widow clothes, on her bag, split open on the floor, spilling foilwrapped condoms like treasure' (p.15). As Trites points out, 'death and sex are cultural and biological concepts that are linked inviolably' (2000, p.122). In these scenes, however, notions of sex and death are closely intertwined with femininity also, making it difficult not to connect Janey's death with her way of being female. According to Bradford, Janey dies of 'an excess of femaleness' because she is driven purely by her sexuality; she is constructed as 'subject to corporeality, ruled by the phases of the moon and of her menstrual cycle' (1998, pp.114,116). From a patriarchal perspective, then, the figure of Janey is, to use Mallan's term, a 'disruptive feminine presence' that must be 'silenced and annulled' (2002a, p.180) and she is, therefore, killed off. Significantly, this occurs at the very place where she often goes to have sex: she is raped and beaten, and when Chloe finds her, her dead body is displayed in a manner which 'incites a sexualising gaze' (Mallan 2002b, p.43) since she is naked and positioned lying on her back. Almost in a grotesque parody of orgasm (or, symbolically, in preparation to submit to the phallic order), her mouth and eyes are open and she is draped across the back of a car, an object often associated with the masculine (p.103). Janey can transgress the hetero-normative construct of female sexuality, the text appears to say, but she will pay for her sexual aggression. This is emphasised by Chloe's mother, Joy, when she informs Chloe 'that most people don't do sex like that' (p.120). Consequently, Janey's death is violent, evident in the look of 'glazed surprise' fixed to her (dead) face, her body 'marked up and down with bruises', a cape of blood flowing 'down around her from the back of her head and off over the edge of the boot' (p.104). Here, death has not caused a 'destruction of the gendered body', 
but has rather ensured the 'objectification of the woman's body-as-image' (Mallan 2002b, p.44), because, as Chloe notes after placing a coat over Janey, covered and with her eyes closed she looks only like an accident victim rather than a victim of a violent sex crime (p.105). ${ }^{5}$

Admittedly, there are moments when Janey's sexuality is privileged by the text. Wilson points to one episode where, unable to wait until evening, Janey chooses to have sex during a lunch break at school (2001, p.27). In contrast to the descriptions of the disgusted, bitchy and cold girls who whisper about her afterwards in the classroom, Janey is represented in positive terms: her 'lips are very red and her eyes and skin are as bright as dew with sunlight on it' (p.123). In another, the double standards characterising phallocentric notions of female sexuality are highlighted when a boy Janey has just 'done over' suggests that Chloe is either frigid or a lesbian because of her lack of interest in having sex herself, while in the same breath informing her that boys don't go for girls like her and Janey. 'You're just angry because she calls the shots,' Chloe [replies] ... 'You'd go for her, no worries. She wouldn't want you to stick around, though - that's why you don't like her' (pp.12-13). Janey's clear enjoyment of her sexuality and her body, and the subversive use of her father's pornographic magazines to create a decoupage egg in craft class, covered with 'strange pink leaves and buds ... little vagina-mouths surrounded by petals of thigh and breast and bottom'(p.118) also provide evidence of feminist agendas and strategies (Bradford 1998, p.114).

As Bradford (1998) and Wilson (2001) argue too, at numerous points the text attends to resisting male universal norms by encouraging readers to resist dominant ideas about female sexuality. These disruptions and contradictions are noticeable, for instance, in passages where Janey questions the notion of romantic sex, either with her behaviour or her words, where Janey's courage and curiosity is privileged over Chloe's docility and timidity, and where the girls' relationship is shown to be of paramount importance. The latter occurs regularly in the narrative, demonstrating the power of the bonds that bind Chloe and Janey to each other: Chloe chooses Janey over her lover, Theo; the girls hug and laugh about jealous boys who feel excluded by their intimacy; and Chloe articulates her feelings for
Janey in words that entirely transcend all others she uses to describe her relationships: ' ... it isn't something she thinks about any more than a magnet thinks about snapping onto the fridge-it's not a matter of discussion or agreement that keeps them together, but an unquestioning force' (p.148).

Kate McInally's reading of the text (which approaches Chloe and Janey's relationship in terms of same-sex desire) discloses similar ideas since it suggests that these points of intense connection between the girls can be seen to coalesce into an image of 'the positivity and possibilities of girls' desires for each other'. With its refusal to align desire with dominant definitions of what constitutes a sexual relationship, and to engage with a conventional linear reading that prioritises closure, she argues, this 'rhizomic' reading of the text works to resist patriarchal maturational models of subjectivity (2004,pp.1,6,8). Under these terms, Chloe and Janey's close and passionate relationship is a celebration of female desire, and Janey's death can be viewed not as the event that forces the girls apart, but the one that draws them permanently together. This is clearly evident in the episode when Chloe visits the crematorium garden where Janey's ashes are scattered. Here, readers are positioned to accept growth (even amidst death) as a positive value because there is sense of optimism pervading the scene, signalled by the emphasis on closure for Chloe, by the acknowledgment that the girls will always be bound together, and by the association between death, jonquils and humour:

But sitting alone here, she doesn't feel any urge to speak aloud, to whatever is left of Janey here, whatever hasn't blown away in the smoke. What's left that isn 'tjonquils, it seems to Chloe, is scattered through Chloe's life, and Chloe's family's, as comprehensively as a Kleenex through a load of washing. It's just there, in their bones and brains and speech patterns, built into their sense of humour and each of their separate histories.

(p.208)

However, I would argue that because the text also constructs Janey's death as a fait accompli (Wilson 2001, p.29), these incidents, as a whole, become little more than a surface ideology which ultimately fails to disturb the more 
pervasive message underscoring the novel (that is, that female sexuality is abject). In fact, Janey's deathly fate is evident almost from the outset. She conducts her 'trysts' at an auto-wrecking lot, for instance - a graveyard of rusted car bodies and parts, infested with rats, from which at one point, she emerges 'like some kind of mysterious extrusion from [their] corpses' (p.14). Another scene links her with decay when she is described as 'all black-legginged legs, with a tiny snarled black jumper, like a wisp of some kind of mould around her shoulders and arms' (p.30). Thus, although after the court case, Chloe thinks how arbitrary the accident was 'a matter of timing and slips in someone's concentration ... and the wrong constellation of people and fluids' (p.164), she also feels that she has 'been drawing this one event towards her all her life', has known without admitting it, the danger surrounding Janey:

Police, morgues, injuries-she's gone along in all innocence, never dreaming these words might be used of Janey, but now that she looks back, of course they were coming-she should have seen them flapping like vultures over Janey all along, from way back in the schoolyard, and in a tall column spiralling up on the thermals of evil grotty heat from Janey's house.

$$
\text { (p.113) }
$$

Chloe and her mother accept some responsibility for Janey's death - Chloe for her choice to leave Janey in a distressed state after she has been raped by her brother, Nathan, and Joy for her own passivity-for not doing more to avert the looming tragedy. Joanna Harris argues that the episode when this occurs provides evidence of Chloe's maturation into adulthood. It is also presented in a way which suggests that an adult view of the situation is a complex one: a 'realistically' unresolved and unresolvable way of seeing (1999, p.44), because although Chloe feels culpable she also firmly reassures her mother 'we're not the ones on trial ... [we're] not the ones who did it' (p.182). This statement is echoed by Chloe's father, Dane, when he says 'it was 'just bad luck as much as anything' (p.120). However, as Harris also argues, it is at moments like these that the novel's impression of realism becomes a powerful ideological tool since they assist in promoting a 'misleadingly simple perspective to explain the circumstances of Janey's murder'.
Rather than 'extending an understanding of the social forces which shaped Janey's existence', she argues, this scene merely reinforces the idea that Janey was destined to die (1999, p.44). By the novel's conclusion, this has become abundantly clear: Janey has been replaced by Isaac, Chloe's new boyfriend - and 'the corrective to all Janey's flaws' - creating a romantic and conventional closure that is only possible in narrative terms because of Janey's death (Bradford 1998, p.116).

In Wilson's words, 'those who transgress and who are subsequently abjected are an example to all to conform to the regulations imposed' (2001, p.28). As I have argued, this is made especially clear in the text by the association between Janey's non-conformity and her violent murder. Several episodes, in particular, highlight this idea, not least those detailing Janey's promiscuity, but also those that make reference to the sexual relationship she has with her father and brother, and her unplanned pregnancy. Like other adolescent novels featuring teenage pregnancies, this one operates as a cautionary tale relating to the dangers of teenage sexual activity. According to Trites, authors who depict young adults experiencing extreme sexual pleasure tend to minimise the repressive use of ideology, in part by allowing characters to feel empowered by their sexuality (2000, p.96). In this instance, however, rather than gaining a sense of empowerment from her obvious enjoyment of sex, Janey is punished. Not only does she suffer depression and moments where she 'hates herself' as a result of relinquishing her child after the pregnancy, she is disempowered by the knowledge that this occurred in spite of the responsibility she took for contraception: 'I guess, you know, statistically ... [t] he number [of condoms] I use, I'd have to get a dud some time' (p.157). Here, the anxieties surrounding adult views of adolescent sexuality are clear. Disturbingly, they intersect with another set of ideologies concerning maternity, sexual abuse and class, for it is suggested that the quality of Janey's mothering skills has been predetermined, and that the potential to harm her child is a given. It is as if, the text implies, she has inherited a gene that will ensure she is 'hopeless', and always doubting her ability to 'stop the tradition': 'You hear, you know, how "abused" people abuse their kids and I ... just wonder, is that something you could control?' 
(p.159). Spoken from within the 'generalised niceness' of Chloe's house, where everything is organised and clean, and parents are helpful and caring, this statement only adds to the sense that Janey's freedom of choice is entirely limited by her social situation.

Where the brutality of Janey's existence manifests itself in episodes of sexual abuse, the connections between class difference, sexual pathology and Janey's death are particularly evident, for it is these incidents that point to the extent to which she has disturbed the social order, and thus also to her abjection. In the adolescent novel, Trites argues, 'nothing demonstrates the power relationships between adults and adolescents as effectively as the abuse of sexual power'(2000,p.96). As a function of the narrative plot, Janey's sordid home life provides the reason for her escape to, and refuge within, the Hunter household. In fact, the novel opens with Janey declaring: 'I've got to get out of that house' (p.7), followed by juxtaposing representations of Janey's depressing search for new accommodation and her 'dirty old man' with Chloe's liberal, friendly home and her 'civilised brothers' (Harris 1999, p.42). Both Janey's father and brother have been sexually abusing her for some time, and her fear of them is demonstrated by the lengths she will go to in order to conceal from them any details pertaining to her new life, even when this involves drastically changing her appearance. Under these circumstances, the power the men have over Janey is explicit. At a discursive level, however, readers are positioned to view Janey's abuse, including the later rape by Nathan, as a consequence of her subversive sexuality. Drawing on the familiar (patriarchal) image of the woman with the short skirt who is 'just begging' to be raped, the text suggests that Janey's casual and often aggressive approach to sex means that she has foregone her right to refusal in any sexual encounter. This is illustrated firstly by Chloe's question about how Janey feels in regard to the abuse, to which she replies: 'who am I to complain?' (p.38), and secondly by Janey's mother who is constructed as ineffectual and blank, but also - with her pretence that nothing untoward is happening - complicit in the crime. The significance of these small, but meaningful, snippets of information is then imposed retrospectively when they are drawn together at a point later in the narrative (importantly, after the scene involving Janey's death) when Chloe asks Dane: 'Is it child sexual abuse if the child doesn't really mind the sex?' (p.136).

In conclusion, Touching Earth Lightly demonstrates the power of discourse to communicate notions of "normality' as they relate to sexual practices. It suggests that 'alternative' forms of sexuality are perverse and that there is a distinct 'division between licit and illicit' (Foucault 1978, p.37) because, regardless of the narrative's attempts to work against conventional ideas about acceptable sexual behaviour and ways of being female, it ultimately implies that Janey's death occurs as the result of a violation of the rules governing sexual experience. The novel's pervasive emphasis on the unusualness of Janey's life and ways of being also constructs a very definite picture for readers of what 'the norm' should be. As Foucault's theories have demonstrated, when so much attention is paid to sex and sexuality, it is difficult not to focus on it, to think about what is approved and what is not (Danaher, Schirato \& Webb 2000, p.144). Moreover, with its conventional closure that is dependent upon the transferral of Chloe's passion from Janey to Isaac, the text not only illustrates the pervasiveness of the heterosexual romance model, it also suggests that 'being female is to fit within social and ideological structures created and sustained by masculine desires' (Bradford 1998, p.115). As McInally contends, the narrative clearly specifies that Isaac, rather than Janey, affords Chloe healthy psychosexual resolution, and that, like other texts featuring desire between young female characters, it too can be seen to represent girls' passions for each other as merely a stage in the journey towards attaining a (fixed) heterosexual identity (2004, pp.1,4).

That the novel's romantic outcome involves Janey's death perhaps says something about the threat that female-tofemale desire poses to the patriarchy as well, for in killing Janey off and replacing her with the far more suitable Isaac, the conclusion to the text locates the female subject firmly within phallocentric systems of representation (Bradford 1998, pp.115-116). It is in this way too that Janey's 'dangerous' sexuality is contained because her death can be read as an extreme form of implementing closure against the liminal and disturbing aspects of the feminine by removing such destructive forces from the masculine 
economy (Bronfen 1992, p.219). Indeed, the narrative discloses a pronounced anxiety regarding female power suggesting, as Bronfen and Goodwin argue, that in order for a culture to define its own boundaries, it needs 'images of alterity and sacrifice'-which, at the extreme, can be seen as 'those it chooses to kill, literally and symbolically' (1993, pp.15-16).

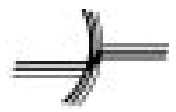

\section{NOTES}

1. I owe a debt to Elisabeth Bronfen's Over Her Dead Body: Death, Femininity and the Aesthetic (1992) for this title.

2. This double movement between repulsion or exclusion and attraction or intrusion is what Bataille terms 'abjection' (Hegarty 2000, pp.61-62).

3. The term 'Being-towards-death' appears in Martin Heidegger's Being and Time (1962). In Trite's words, Heidegger argues that it 'represents the moment of maturation in which the subject defines himself in terms of his own death, in terms of his own not being' (2000, p.159).

4. In this paper, Wilson also discusses Judith Clarke's Night Train (1998), a text which offers an interesting examination of the degenerative effects of abjection on the development of adolescent subjectivity. Here, the narrative implies that the protagonist, Luke, dies, like Janey, as a result of 'society's inability to deal with individuals who do not conform to the majority's construction of "normal"" (2001, p.29).

5. Mallan's ideas for this argument are drawn from Bronfen (1992).

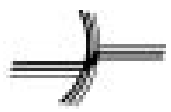

\section{REFERENCES}

Aaron, Michele (1999) 'Introduction', in M.

Aaron (ed) The Body's Perilous Pleasures:

Dangerous Desires and Contemporary
Culture. Edinburgh, Edinburgh University Press, pp.1-10.

Bataille, Georges (1986) Erotism: Death and Sensuality (1st City Lights Reprint edn), trans. M. Dalwood. San Francisco, City Light Books.

Bradford, Clare (1998) 'Embodied subjectivities: Female-authored texts and female friendships', in S. Clancy \& D. Gilbey (eds) Something to Crow About: New Perspectives in Literature for Young People: Centre for Information Studies, Charles Sturt University, pp.109-117.

Bronfen, Elisabeth (1992) Over Her Dead Body: Death, Femininity and the Aesthetic. Manchester, Manchester University Press.

Bronfen, Elisabeth and Sarah Webster Goodwin (1993) 'Introduction', in S. W. Goodwin \& E. Bronfen (eds) Death and Representation. Baltimore, Johns Hopkins University Press, pp.3-25.

Clarke, Judith (1998) Night Train. Ringwood, Penguin.

Creed, Barbara (1993) The Monstrous Feminine: Film, Feminism, Psychoanalysis. London, Routledge.

Danaher, Geoff, Tony Schirato and Jen Webb (2000) Understanding Foucault. St Leonards, Allen \& Unwin.

Foucault, Michel (1978) The History of Sexuality, Volume One: An Introduction, trans. R. Hurley. London, Penguin.

Gilbert, Sandra M and Susan Gubar (1979) The Madwoman in the Attic: The Woman Writer and the Nineteenth-Century Literary Imagination. New Haven, Yale University Press.

Gilman, Sander L. (1993) "“Who kills whores?” "I do," says Jack: Race and gender in Victorian London', in S. W. Goodwin \& E. Bronfen 
(eds) Death and Representation. Baltimore, Johns Hopkins University Press, pp.263-284.

Grosz, Ellizabeth (1990) 'The body of signification', in J. Fletcher \& A. Benjamin (eds) Abjection, Melancholia, and Love: The Work of Julia Kristeva. London, Routledge, pp.80-103.

Harris, Joanna (1999) 'Good girls don't: Gender ideologies in Touching Earth Lightly and Wolf', Papers: Explorations into Children's Literature 9,1: 41-50.

Hegarty, Paul (2000) Georges Bataille: Core Cultural Theorist. London, SAGE.

Heidegger, Martin (1962) Being and Time, trans. J. Macquarie \& E. Robinson. New York, Harper and Row.

Kristeva, Julia (1982) Powers of Horror: An Essay on Abjection, trans. L. S. Roudiez. New York, Columbia University Press.

Lanagan, Margo (1996) Touching Earth Lightly. St Leonards, Allen \& Unwin.

Mallan, Kerry (2002a) 'Fatal attractions: Death, femininity and children's literature', in G. Bull \& M. Anstey (eds) Crossing the Boundaries. Frenchs Forest, Prentice Hall, pp.175-190.

Mallan, Kerry (2002b) 'Just looking? The body, the gaze and the male artist', in S. Pearce \& V. Muller (eds) Manning the Next Millennium: Studies in Masculinities. Bentley, Black Swan Press, pp.41-52.

McCallum, Robyn (1999) Ideologies of Identity in Adolescent Fiction: The Dialogic Construction of Subjectivity. New York, Garland.

McInally, Kate (2004). Reading girls' desire in Touching Earth Lightly, paper presented at 'Imaging Childhood', Australasian Children's Literature Association for Research conference, University of Technology, Sydney, Centre for Research and Education in the Arts, 17 July.

McNay, Lois (1994) Foucault: A Critical Introduction. Cambridge, Polity Press.

Rivkin, Julie and Michael Ryan (1998) 'The class of 1968 - post-structuralism par lui-même', in J. Rivkin \& M. Ryan (eds) Literary Theory: An Anthology. Malden, Blackwell, pp.333357.

Tanner, Laura E. (1996) 'Death-watch: Terminal illness and the gaze in Sharon Old's The Father', Mosaic (Winnipeg) 29,1: 103-121.

Trites, Roberta Seelinger (2000) Disturbing the Universe: Power and Repression in Adolescent Literature. Iowa, University of Iowa Press.

Tseëlon, Efrat (1995) The Masque of Femininity. London, SAGE.

Wilson, Kim (2001) 'Abjection in contemporary Australian young adult fiction', Papers: Explorations into Children's Literature 11,3: 24-31.

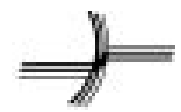

\section{BIOGRAPHICAL NOTE}

Kathryn James completed a PhD in Literary Studies at Deakin University, Melbourne, in late 2005. Her thesis, entitled 'Matilda's Last Dance: Death, Gender, Sexuality and Australian Adolescent Literature' (from which this article is drawn), examined various treatments and representations of death in a selection of contemporary texts aimed at adolescent readers. Kathryn's publications and research interests are in the areas of transgressive and carnivalesque literature, visual texts, popular culture, gender theory, landscape representation, and national identity. 